Bangladesh Journal of Neuroscience 2019; Vol. 35 (2): 63-68

\title{
Demographic and Clinical Pattern of Headache in Migraine Patients
}

\author{
MAJUMDER B ${ }^{1}$, PAUL $D^{2}$, BARMAN KK ${ }^{3}$, FERDOUSHI $S^{4}$, ISLAM MR ${ }^{5}$, ROY NR ${ }^{6}$, \\ SALEHEEN MS ${ }^{7}$, ISLAM MM ${ }^{8}$
}

\begin{abstract}
Background: Migraine is one of the most common neurological disorder and fourth most important factor for debility in human. The presentation of migraine is complex. All patients do not have same features of migraine. Objectives: The purpose of the study was to evaluate demographic and clinical patterns of headache in migraine patients. Methods: A total of 30 migraine patients who were visited in the Headache clinic, Department of Neurology, BSMMU, Dhaka were enrolled for the study. Migraine patients diagnosed according to ICHD-3 (International Classification of Headache Disorders $3^{\text {rd }}$ edition) criteria. Results: Out of 30 patients mean age was $30.63 \pm 10.95$ years with age range 15-60 years in migraine patients. Female were more common. Positive family history was present in $56.7 \%$ patients. Common associated symptoms were photophobia, phonophobia (96.7\%) and nausea (83.3\%) in migraine patients. Common precipitating factors were stress and sunlight (90\%) followed by journey (80\%) and insomnia (73.3\%). A major portion of migraine was without aura (73.3\%) and the ratio of aura to without aura is 1: 2.75. Major portion of migraine patients were complained of 4-6 attacks/ month (46.7\%) which was followed by 1-3 attacks/month (36.7\%). Most of the migraine patients complained as moderate headache (60\%) followed by severe headache $(40 \%)$. Conclusion: This study concluded that migraine is a disease of younger age group and it affects female more commonly than male, pattern of headache in migraine patients is unique.
\end{abstract}

\section{Introduction:}

Migraine is the primary headache disorder and the second most common neurological (next to nutritional disorders and neuropathies) problem throughout the world ${ }^{1}$. Annually it affects $12 \%$ population of the United States. It includes 18\% women, $6 \%$ men and $4 \%$ children in the United States. Overall, the 1-year prevalence of migraine ranged from $3.0 \%$ in aged $11-14$ years and $10.6 \%$ in age ranging from 5-15 years ${ }^{2}$. All the subtypes of migraine were more common in females ${ }^{3}$ which is also consistent with the study done in Bangladeshi populations ${ }^{4}$.
Migraine is a familial disorder characterized by recurrent attack of headaches widely variable in intensity, frequency and duration. Attacks are commonly unilateral and are usually associated with anorexia, nausea and vomiting ${ }^{5}$. In some cases, they are preceded by or associated with neurological and mood disturbances. Migraine sufferers typically have unilateral headache but it may be bilateral and complain of throbbing headache but equally it may be constant. They usually have some degree of nausea and/ or vomiting and often have sensitivity to light (photophobia) or sensitivity to sound

1. Dr. Bipasha Majumder, Medical Officer, Dept. of Laboratory Medicine, DMCH, Dhaka.

2. Dr. Debatosh Paul, Associate Professor, Dept. of Laboratory Medicine, BSMMU, Dhaka.

3. Dr. Kanuj Kumar Barman, Associate Professor, Dept. of Neurology, BSMMU, Dhaka.

4. Dr. Sheuly Ferdoushi, Associate Professor, Dept. of Laboratory Medicine, BSMMU, Dhaka.

5. Prof. (Dr.) Md. Rafiqul Islam, Professor and Chairman, Dept. of Neurology, BSMMU, Dhaka.

6. Dr. Niloy Ranjan Roy, IMO, Dept. of Neurology, DMCH, Dhaka.

7. Dr. Md. Shafiqus Salehin, Assistant Professor, Dept. of Neurology, M Abdur Rahim Medical College, Dinajpur

8. Dr. Md. Monirul Islam, Registrar (Medicine), Satkhira Medical College, Satkhira 
(phonophobia) $^{6}$. Normal physical activity that involves movement of the head aggravates the pain. Human biology knows few rules that do not have exceptions and many patients did not have all the features of migraine ${ }^{7}$.

The presentation of migraine is complex. Two common clinical syndromes associated with migrainous headache can be identified easily that is migraine with aura and migraine without aura. Migraine with aura is called classical or neurologic migraine and migraine without aura is known as common migraine. The ratio of classical to common migraine is $1: 5^{8}$.

Some precipitating factors for headache are fatigue, stress, anxiety, cold, warm, sunlight, sleep deprivation/insomnia, food, activity, journey, reading etc. There are 5 relieving factors of headache such as sleep, drug, rest, posture, massage ${ }^{9}$.

\section{Aims and objectives:}

To evaluate the demographic and clinical pattern of headache in migraine patients.

\section{Materials and Methods:}

This cross sectional analytical study from March, 2018 to February, 2019 was conducted in the Department of Laboratory Medicine, BSMMU, Dhaka, collaboration with the Department of Neurology, BSMMU, Dhaka. After ethical clearance from Institutional Review Board (IRB), patients having features of migraine according to ICHD-3 (International Classification of Headache Disorders, $3^{\text {rd }}$ edition) was selected as study population by purposive sampling method.

Total 30 headache patients selected from headache clinic of outpatient department of Neurology of BSMMU. Age range of study group was $10-60$ years. Informed written consent was taken from each patient.

\section{Results:}

The study included 30 migraine headache patients. Table I shows age group of study population, where the maximum number of patient $12(40.0 \%)$ in 21 30 age group. The mean age was $30.63 \pm 10.95$.
Table-I

Age distribution of study subjects $(n=30)$

\begin{tabular}{lc}
\hline Age of the patient & $\begin{array}{c}\text { Migraine headache } \\
\text { patient }(\mathrm{n}=30) \\
\text { No. }(\%)\end{array}$ \\
\hline$<20$ & $5(16.7)$ \\
$21-30$ & $12(40.0)$ \\
$31-40$ & $9(30.0)$ \\
$41-50$ & $3(10.0)$ \\
$51-60$ & $1(3.3)$ \\
Total & $30(100.0)$ \\
Mean \pm SD & $30.63 \pm 10.95$ \\
\hline
\end{tabular}

Table-II

Gender distribution of study subjects $(n=30)$

\begin{tabular}{lc}
\hline Gender & $\begin{array}{c}\text { Migraine headache } \\
\text { patient }(n=30) \\
\text { No. }(\%)\end{array}$ \\
\hline Male & $3(10.0)$ \\
Female & $27(90.0)$ \\
Male: Female ratio & $1: 9$ \\
\hline
\end{tabular}

Table II shows the gender distribution of patients. Among 30 respondents $10 \%$ were male and $90.0 \%$ were female.

Table-III

Distribution of the study subjects by occupation $(n=60)$

\begin{tabular}{lc}
\hline Occupation & $\begin{array}{c}\text { Migraine } \\
\text { headache patient }(\mathrm{n}=30) \\
\text { No. }(\%)\end{array}$ \\
\hline Service holder & $3(10)$ \\
Business & $0(0)$ \\
Housewife & $15(50)$ \\
Others & $12(40)$ \\
\hline Total & $30(100)$ \\
\hline
\end{tabular}

Table-III shows maximum $50.0 \%$ patients were housewife, $10 \%$ patients were service holder and $40.0 \%$ patients had other profession.

Figure-1: Bar diagram showing the family history of migraine headache patient $(n=30)$ 


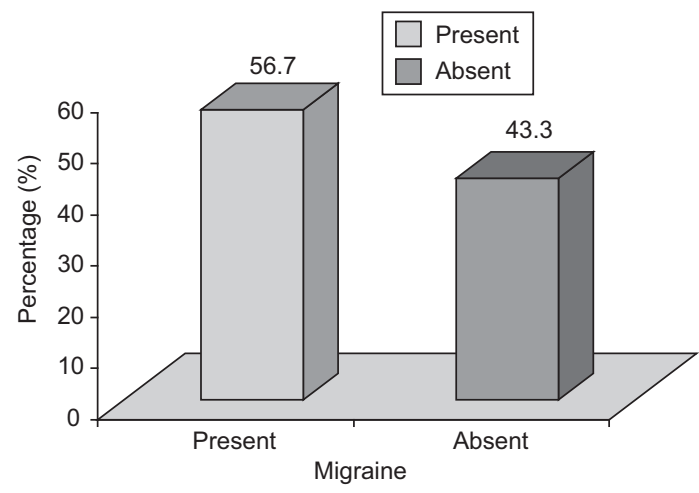

Fig.-1: Bar diagram shows maximum patients $56.7 \%$ had positive family history and $43.30 \%$ having no family history of migraine.

Figure-2: Bar diagram showing the severity of the headache in migraine patients $(n=30)$.

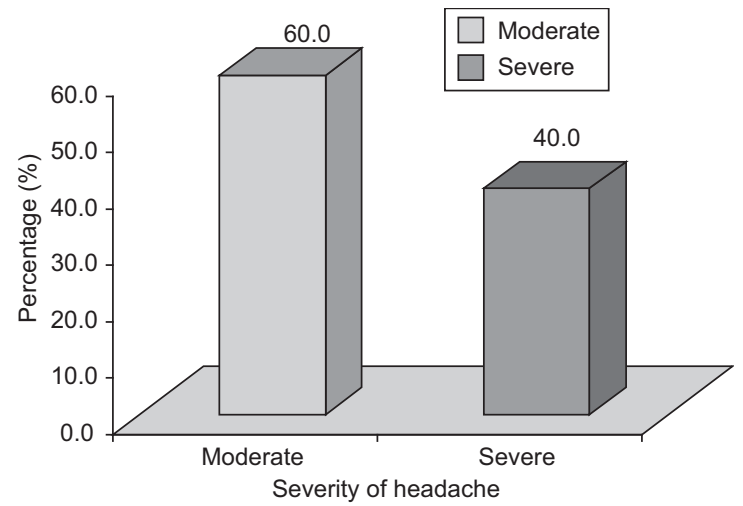

Fig.-2: Bar diagram shows maximum patients $60 \%$ had moderate headache and $40.0 \%$ severe headache.

Figure 3: Pie chart shows that a major portion of migraine patients were without aura (73.3\%). Only $26.7 \%$ migraine patients gave history of experiencing aura.

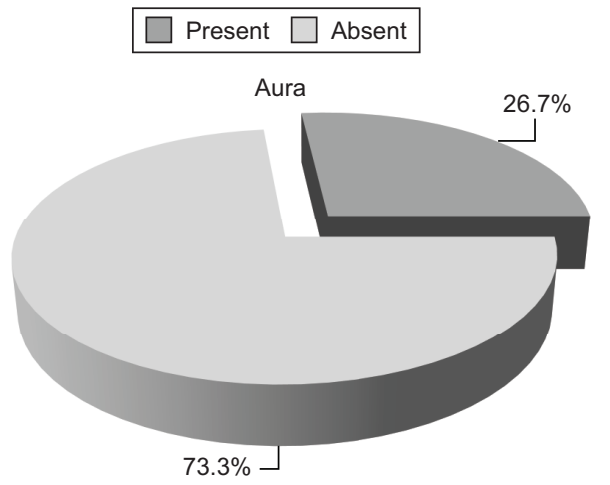

Fig.-3: Pie chart showing distribution of migraine headache patient according to aura $(n=30)$
Table-IV

Distribution of the migraine headache patient by frequency of attacks per month $(n=30)$

\begin{tabular}{lcc}
\hline $\begin{array}{l}\text { Frequency of attacks } \\
\text { per month }\end{array}$ & $\begin{array}{c}\text { No. of } \\
\text { the Patient }\end{array}$ & Percentage \\
\hline $1-3$ & 11 & 36.7 \\
$4-6$ & 14 & 46.7 \\
$7-9$ & 3 & 10.0 \\
$10-12$ & 1 & 3.3 \\
$13-15$ & 1 & 3.3 \\
\hline Total & 30 & 100.0 \\
\hline
\end{tabular}

Table-IV shows frequency of attacks of headache per month maximum $46.7 \%$ in $4-6$ times, $36.7 \%$ patients had $1-3$ times, $10.0 \%$ patients had $7-9$ times and $3.3 \%$ patients had $10-12$ times and $13-$ 15 times.

Table-V

Distribution of the migraine headache patient with associated symptoms $(n=30)$

\begin{tabular}{lcc}
\hline Associated symptom & Frequency & Percentage \\
\hline Nausea & 25 & 83.3 \\
Vomiting & 12 & 40.0 \\
Vertigo & 21 & 70.0 \\
Phonophobia & 29 & 96.7 \\
Photophobia & 29 & 96.7 \\
Difficulty in concentrating/ & 28 & 93.3 \\
Feeling lightheadedness & & \\
\hline
\end{tabular}

Table- $V$ shows that the most common announcing associated symptoms were nausea $(83.3 \%)$, phonophobia and photophobia (96.7\%) in migraineurs.

\section{Table-VI}

Distribution of the migraine headache patient with precipitating factors $(n=30)$

\begin{tabular}{lcc}
\hline Precipitating factors & Frequency & Percentage \\
\hline Stress & 27 & 90.0 \\
Journey & 24 & 80.0 \\
Sunlight & 27 & 90.0 \\
Insomnia & 22 & 73.3 \\
Deprivation of food & 5 & 16.7 \\
Menstruation & 2 & 6.7 \\
OCP & 8 & 26.7 \\
\hline
\end{tabular}


Table-VI shows that a major portion of migraine patients proclaimed stress $(90 \%)$, sunlight exposure $(90 \%)$ as precipitating factors for migraine which was followed by journey $(80 \%)$ and insomnia $(73.3 \%)$.

Table-VII

Distribution of the migraine headache patient with relieving factors $(n=30)$

\begin{tabular}{lcc}
\hline Relieving factors & Frequency & Percentage \\
\hline Rest & 27 & 90.0 \\
Sleep & 28 & 93.0 \\
Massage & 22 & 73.0 \\
Others (Hot \& cold & 03 & 10 \\
compression) & & \\
\hline
\end{tabular}

Table-VII shows that reported relieving factors of migraine patients are rest (90\%), sleep (93\%) and massage $(73 \%)$.

\section{Discussion:}

This cross sectional study was carried out to see the demographic variations among the migraine headache patient. In this study, it was observed that maximum number of patient $12(40.0 \%)$ in the age group 21-30. The mean age was $30.63 \pm 10.95$. Mean age $39.6 \pm 11.1$ and $37.7 \pm 11.1$ years respectively were also found ${ }^{10}$. Some study shows that migraine may start in early childhood. But its prevalence increases at 10 to 14 years of age and continues to increase until 35 to 39 years of age. Then it gradually decreases, particularly women after menopause ${ }^{11}$. These results are nearly similar to our study.

Among 30 respondents $10 \%$ male and $90.0 \%$ females were migraine headache patients. Female respondents were predominant. Female groups were more prone to develop migraine $69.3 \%$ and $81.7 \%$ respectively ${ }^{12,13}$.

A major portion of migraine patients were housewife $(50 \%)$ which was followed by student or other $(40 \%)$. Housewife were the large group $(28.6 \%)$ followed by student $(17.6 \%)$ found in another study ${ }^{14}$. These are almost similar with our study. The possible reason may be in our country the housewives are more exposure to many provocative factors like physical and mental stress, irregular of food, menstruation, birth control pill intake etc.

Migraine has a strong genetic component and the familial risk of migraine is increased as exhibited by population-based family studies ${ }^{15}$ which coincides with our study where $56.7 \%$ of migraine patients had family history of migraine headache.

Migraine headache severity was divided into mild, moderate and severe group according to visual analogue scale. Among the migraine patients, most of the patients complained of moderate headache which is about $60 \%$ followed by severe headache $(40 \%)$. But no one complained headache severity as mild. According to International Classification of Headache Disorder migraine headache severity is moderate to severe intensity ${ }^{16}$ which is also consistent with our study.

Among the 30 migraine patients, 08 (26.7\%) patients had migraine with aura and 22 (73.3\%) patients had migraine without aura and the ratio is $1: 2.75$. Another study ${ }^{17}$ found that among 32 subjects, $26 \%$ (7) patients had migraine with aura and $74 \%(20)$ patients had migraine without aura, ratio was 1:2.85 which is almost similar to our study. In another study ${ }^{8}$ found the ratio of migraine with aura to migraine without aura is $1: 5$ which is near to our study.

A major portion of migraine patients were complained of 4-6 attacks/month (46.7\%) which was followed by 1-3 attacks/month (36.7\%). Another study done in this country ${ }^{14}$ reported as $30.76 \%$ patients suffer 3 or less attacks per month and 4 or more attacks in $16.15 \%$ per month.

According to associated symptoms of migraine, the most common announcing associated symptoms were photophobia (96.7\%), phonophobia (96.7\%) and nausea (83. 3\%) in migraine patients. Another study ${ }^{18}$ shows that most common symptoms associated with headaches were phonophobia $(91.6 \%)$ and photophobia (85.4\%).

Most of the migraine patients, proclaimed stress and sunlight as precipitating factors of migraine $(90 \%)$ which was followed by journey $(80 \%)$ and insomnia $(73.3 \%)$. Another study ${ }^{19}$ showed that most common precipitating factors were stress, 
tension, not eating on time, fatigue and lack of sleep. Similar result was ${ }^{20}$ mentioned that the most frequent triggers of migraine were mental exertion, exposure to the sunlight, heat and anxiety.

Most common relieving factor for migraine patients are sleep (93\%) and rest (90\%). Another study ${ }^{14}$ reported analgesic (83\%), sleep (80\%) which is consistent with the present study.

\section{Conclusion:}

This study showed that migraine headache was common in young age group and female predominant. This study may also provide baseline information regarding migraine headache pattern.

\section{References:}

1. World Health Organization estimates, (20022005). Approach to the patient with neurologic disease. In: Harrison's Neurology in Clinical Medicine. 3rd ed. New York: McGraw-Hill education; 2013. P. 2.

2. Lipton RB, Bigal ME. The epidemiology of migraine. The American Journal of Medicine. 2005;118(s1): 3s-10s.

3. Russell MB, Smussen BK, Thorvaldsen P, Olesen J. Prevalence and Sex-Ratio of the Subtypes of Migraine. International Journal of Epidemiology. 1995; 24(3):612-618.

4. Hannan, MA, Hasan MK, Begum A, Haque A. Study of epidemiological features of primary headache patients in a tertiary center in Bangladesh. Bangladesh Journal of Neurosciences. 2007; 23(1): 13-20.

5. Pietrobon D, Striessnig J. Neurobiology of Migraine. Nature review Neuroscience. 2003; 4(5): 386-398.

6. Stewart WF, Lipton RB, Celentano DD, Reed $M L$. Prevalence of migraine headache in the United States: relation to age, income, race and other socio-demographic factors. Journal of American Medical Association. 1992; 267(1): 64-9.

7. Goadsby PJ, Raskin NH. Headache. In: Hauser SL, Josephson SA, editors. Harrison's Neurology in Clinical Medicine. $4^{\text {th }}$ ed. New York: McGraw-Hill Education; 2015. p. 376-385.
8. Ropper AH, Samuels MA and Klein JP. Headache and other craniofacial pain. In: Adams and Victor's Principles of Neurology. $10^{\text {th }}$ ed. New York: McGraw-Hill Education; 2014. p. 172-83.

9. Haque B, Rahman KM, Hoque A, Hasan AH, Chowdhury RN, Khan SU, et al. Precipitating and relieving factors of migraine versus tension type headache. BMC Neurology. 2012; 12 (1):1-4.

10. Assarzadegan $F$, Asgarzadeh $S$, Hatamabadi HR, Shahrami A, Tabatabaey A, Asgarzadeh $M$. Serum concentration of magnesium as an independent risk factor in migraine attacks: a matched case-control study and review of the literature. International Clinical Psychopharmacology. 2016; 31(5): 287-292.

11. Charles A. Migraine. New England Journal of Medicine. 2017; 377(6):553-61.

12. Gozke E, Unal M, Engin H, Gurbuzer N. An Observational Study on the Association between Migraines and Tension Type Headaches in Patients Diagnosed with Metabolic Syndrome. ISRN Neurology. 2013;1-4.

13. Rana MM, Anwarullah AKM, Mohammad QD, Islam MR, Rahman HZ, Bhuiyan M, et al. Sodium Valproate is More Effective than Pizotifen in the Prophylaxis of Migraine Patients. Bangladesh Journal of Neuroscience. 2012; 28(2):81-87.

14. Barman KK, Islam MR, Anwarullah AKM, Khan AKH, Masihuzzaman SAM,Uddin MJ. Characteristics of headaches in migraine patients. Bangladesh Journal of Neuroscience. 2010; 26(2): 74-77.

15. Russell M, Olesen J. The genetics of migraine without aura and migraine with aura. Cephalalgia. 1993;13(4): 245-48.

16. Headache Classification Committee of the International Headache Society. The International Classification of Headache Disorders. $3^{\text {rd }}$ Edition. London:Cephalagia. 2018; 38(1): 1-211. Available from: https://www.ichd-3.org/DOI: 10.1177/0333102417738202. 
17. Bokhari FA, Shakoori TA, Hasan SAA, Qureshi HJ, Qureshi GA. Plasma homocystine in patients of migraine without aura. Journal of Ayub Medical College Abbottabad. 2010; 22(2):52-55.

18. Assarzadegan F, Asadollahi M, Derakhshanfar $\mathrm{H}$, Kashefizadeh A, Aryani O, Khorshidi M. Measuring Serum Level of lonized Magnesium in Patients with Migraine. Iran J Child Neurol. Summer 2015; 9(3):13-16.
19. Spierings ELH, Ranke AH, Honkoop PC. Precipitating and Aggravating Factors of Migraine Versus Tension-type Headache. The journal of head and face pain. 2001; 41(6): 554-58.

20. Houinato D, Adoukonou T, Ntsiba F, Adjien C, Avode DG, Preux PM. Prevalence of Migraine in a Rural Community in South Benin. Cephalalgia. 2010; 30: 162-69. 